\title{
ORGANIZATIONAL INFORMATION SYSTEM ADOPTION: A Network Perspective
}

\author{
Dirk S. Hovorka \\ Kai R. Larsen \\ University of Colorado \\ Boulder, CO U.S.A.
}

\begin{abstract}
As distributed organizations increasingly rely on technological innovations to enhance organizational efficiency and competitiveness, interest in agile environments that enhance the diffusion and adoption of innovations has grown. Although Information Systems has confirmed that social influence factors play an important role in the adoption of technological innovations by individuals, less is understood about the mechanisms within social communication networks that facilitate the flow of social influence and knowledge and about the organizational capacity to acquire and absorb new knowledge. This exploratory study heips to specify interactions and feedback within social communication networks and organizational capacities in a network organization environment. We use an exploratory case study design to document how the flow of knowledge within social communication networks affected the adoption of a large-scale software system in several counties within New York state. Data from decision makers in two comparable network organizations were analyzed for differences in social communication networks and the organization's capability to absorb and exploit new knowledge. The data suggest that information system adoption was influenced by communication processes that reinforced social influences and supported knowledge transfer, and hampered when those processes were absent. Implications for the development of theory about the relationship between social information processing and the ability of an organization to absorb and adopt new technology are discussed.
\end{abstract}

Keywords Information system adoption, organization, social network communication theory, social information processing, absorptive capacity, case studies, netwo:k organizations 


\section{INTRODUCTION}

As investment in computer and information technologies in modern organizations has continued to increase, there has been persistent interest by the Information Systems community in developing models of information systems diffusion and adoption. Traditionally, adoption of information systems is viewed as a slow process involving sequential adoption and implementation stages (Lyytinen and Damsgaard 2001). There is, however, increasing interest in the creation of agile environments that facilitate the adoption of information systems.

Both social networks and capabilities to acquire and exploit new information have been identified as important components of innovation adoption. In the sprit of looking beyond the dominant adoption paradigm (Fichman 2004), the key question this research examines is whether organizational form can create an environment in which organizations can increase agility by strengthening social communication networks and increasing their capacity to acquire and exploit new knowledge. Agility has been defined as "the ability to detect opportunities for innovation and seize...opportunities by assembling requisite assets, knowledge, and relationships" (Sambamurthy et al. 2003, p. 245). Agility, in this sense, is closely aligned with an organization's absorptive capacity or its ability to acquire, assimilate, transform, and exploit new knowledge (Cohen and Levinthal 1990; Zahra and George 2003). In this exploratory case study, we examine the influence of the strategic implementation of an organizational network form on organizational-level information system adoption. Network organizations are characterized by flexibility, decentralized planning and control, and lateral ties with a high degree of integration of multiple types of socially important relations across formal boundaries (Baker 1992; van Alstyne 1997)

By empirically examining an information systems adoption setting within a network organization form, this paper accomplishes two goals: (1) it demonstrates how network characteristics can influence system adoption by affecting the flow of social and informational influence and (2) it proposes an integrated model of select communication network processes and the organizational construct of absorptive capacity. The study examined the voluntary adoption of a state-advocated information system in two network organizations based on consortia. Each consortium was organized by the state government to distribute knowledge in a phased manner from a lead organization to local organizations within the same consortia. This network form is consistent with many large, distributed organizations or cooperative groups desiring to disseminate information. Adoption was identified by the purchase and use of all or part of the stateadvocated information system. A network with a high level of adoption and a network with a low level of adoption provide empirical data to examine communication network characteristics, social information processing, and the absorptive capacity construct leading to the development of an integrated organizational adoption model.

\section{THEORETICAL BACKGROUND}

Research on information systems adoption is often divided into insular domains divided by unit of analysis (individual, group, or organizational) and by differences 
between variable studies and process or stage approaches (Gallivan 2001). Adoption research is frequently based on Roger's (2003) diffusion of innovation framework (for a review see Fichman 2000), which has a broad focus on how communication channels and opinion leaders shape adoption, but does not illuminate the network mechanisms by which variables and constructs interact and become important during adoption. A preponderance of adoption studies based on the technology acceptance model (for a review see Venkatesh et al. 2003) focus on the characteristics of individual adopters, theories of individual behavior, and antecedent variables, but do not address the theoretical underpinnings of the communication networks in which the individuals are embedded (Monge and Contractor 2003). It has been well established that individual behavior is affected by social and informational influence within networks (Sussman and Siegal 2003; Triandis 1980), and research has confirmed the importance of networks in the diffusion process (Swan et al. 1998). But there is little research on process interaction or mechanisms by which social factors become influential in adoption success or failure (Gallivan 2001; Paré and Elam 1997). In addition, some research has questioned the applicability of the diffusion concepts (Larsen 2001) and the conjectures underlying the diffusion model (Lyytinen and Damsgaard 2001), particularly when examining organizational adoption. Adoption of innovation is enabled by access to new ideas (Swan et al. 1998) and reduction of knowledge barriers (Chau and Tam 1997), and recent research views adoption as a socially constructed process with greater proactive participation by adopters than previously conceived (McMaster 2001). Investigation of the network processes that support system adoption is critical, because it provides another level of explanation from an organizational perspective, and further examines the importance of organizational agility in a system development and adoption setting.

The guiding theories selected in this study specifically apply to the context of the knowledge acquisition and absorption that occurs during an adoption process. We examine characteristics of communication networks, social information processing, and absorptive capacity, which are closely aligned with the flow of knowledge, social and informational influence, and capacity to acquire and utilize new knowledge within and among organizations.

\subsection{Characteristics of Social Communication Networks}

Social communication networks are frequently viewed purely as an emergent characteristic (Grandori ad Seda 1995; McKelvey 1997). However, social communication networks can also be strategically formed and supported to encourage knowledge transfer between organizations (Gulati et al. 2000). Network organization forms may be implemented with the intention of strengthening social communication networks to improve knowledge acquisition and transfer. Communication contacts may be formal (with planned meetings, reporting structures, and training) or informal (with social connections through conferences, unplanned discussions, and similar mechanisms). The strength of ties is often defined as the frequency of communication and the degree of the network is defined as the number of direct links with other network members (Monge and Contractor 2003). We posit that social influence variables identified in previous research become important predictors only in the presence of 
formal and/or informal network ties and formulate question 1: Are the strength and degree of network connections positively correlated with system adoption?

\subsection{Social Information Processing}

Social information processing (SIP) is defined as the concept "that individuals may be influenced by cues from others about what to attend to, how to value salient dimensions of workplace phenomenon and how others perceive the same phenomenon" (Rice and Aydin 1991, p. 220). Contact provided by communication networks is the mechanism by which people and organizations are exposed to information, attitudes, and behavior. This exposure increases the likelihood that members of the network will acquire and assimilate knowledge, attitudes, and behaviors from others in the network (Rice 1993). SIP predicts that "socially constructed meaning about tasks, individual's past experiences about tasks, and objective characteristics of the work environment, all influence perceptions, assessments, attitude formation and behaviors" (Rice 1990, p. 34).

Previous studies have identified network-related antecedent variables to adoption intention, for example, subjective norms, social factors, social influence, social norms, or images (Kraut et al. 1998; Venkatesh et al. 2003). Social and informational influence, salient referent groups (Compeau and Higgins 1995) and managerial- and organizational-level support for computer use (Thompson et al. 1991) influence an individual's adoption intention only through the communication network in which the actor is embedded. These factors form a class of social influence variables grounded in SIP theory as well as theories of individual behavior. It is this class of variables that can be used to tie individual adoption studies to organizational-level system adoption through mechanisms defined in network theories.

Transmitted attitudes may have a positive or negative valence (Stuart et al. 2001), leading to processing of the information by potential adopters. Social information may be in different forms but lead to informational influence (Sussman and Siegal 2003) regarding system adoption. We suggest that the characteristics of the communications network itself will determine, in part, the effect of informational influence, social norms, and attitudes leading to question 2: Does the communication network affect adoption by influencing positive or negative social information processing regarding the information technology?

\subsection{Absorptive Capacity}

Absorptive capacity (ACAP) can be conceptualized as a set of organizational abilities to manage knowledge. ACAP relies on both external connections and internal social networks, and thus provides a contrast to the previous theories. Zahra and George (2003) identify four distinct dimensions: acquisition, assimilation, transformation, and exploitation. Within the organization, these dimensions are linked via social integration mechanisms, which can facilitate the distribution and exploitation of knowledge. Social integration may occur informally in social networks, or formally through the use of coordinators. In the context of system adoption, an organization's absorptive capacity is built on network mechanisms for identifying and sharing knowledge and for rewarding 
the transfer of knowledge. The time and resources organizations dedicate to acquiring and distributing information may be critical components for positive adoption. Prior knowledge, diversity of knowledge sources, comprehension, and learning are all indicators of the acquisition and assimilation of knowledge (Cohen and Levinthal 1990; Zahra and George 2003).

Prior work has identified the porosity of firm boundaries and formal and informal network structures that identify responsibilities and competencies (Matusik and Heeley 20045 ) and previous experiences of individuals (Cohen and Levinthal 1990; Taylor and Todd 1995) as contributing to organizational absorptive capacity. These variables emphasize the contribution of network influences and may be incorporated into theoretical network mechanisms leading to question 3: Do communication networks foster overall absorptive capacity leading to information system adoption?

\section{STUDY ENVIRONMENT}

Probation departments are a part of the criminal justice system and provide an alternative to incarceration for criminals whose crimes or family situations justify community inclusion. Traditionally, funding for criminal justice activities has gone to law enforcement, the prison system, and parole. A result is that probation departments historically have lacked the technology needed to improve the efficiency and effectiveness of their core operations.

In June 1996, a survey by the state of New York's probation agency showed that most probation departments relied on paper forms or limited personal computer use. Many probation departments were involved in uncoordinated and nonstandardized information systems development efforts. To encourage electronic record sharing, caseload management, and standard reporting information, as well as other probation activities, a state-wide probation IS project aimed at small- to mid-sized departments was initiated. After extensive network readiness surveys, requirements analysis, and review of proposals from vendors, a specific information system named PROBER was selected for implementation.

In 1997, the 50 local probation departments were organized into eight geographically contiguous networks, called consortia, to facilitate the adoption process. The consortia were intended to support knowledge distribution and sharing, and to make available the expertise about the process required to successfully adopt the system. Two lead departments were chosen to help customize, document, and provide final acceptance of the selected vendor's software. Both lead departments were encouraged to schedule meetings, provide support by distributing solutions to problematic processes, and involve the counties of their consortium in the process of preparing for the new system.

\section{METHOD}

The two consortia selected for comparison in this study had different levels of system adoption (see Figure 1). Although the grouping of counties was designed to create 


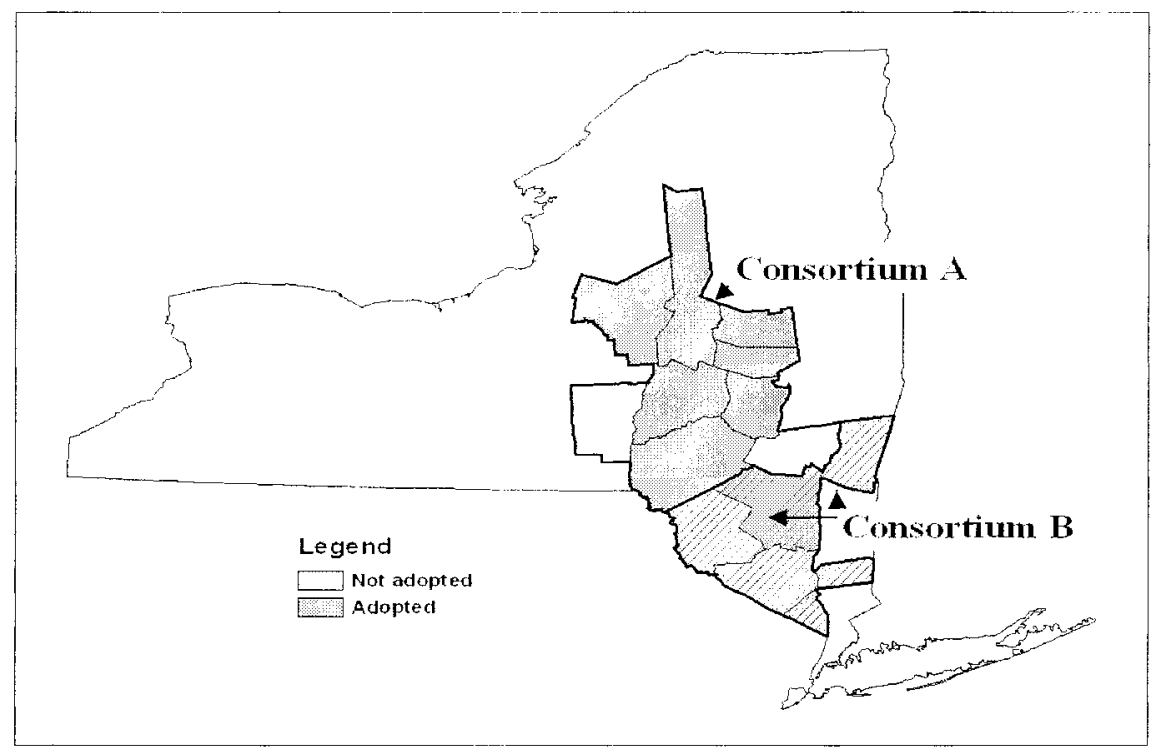

Figure 1. Adoption by Counties Within Each Consortium

consortia with similar characteristics, the difference in percentage of counties of each consortium which adopted the system ( 78 percent versus 17 percent) raises questions regarding why the differences occurred. These consortia were the first two involved in the adoption process and had the longest involvement with the consortia network that initiated the adoption effort

The two consortia were also similar in how they tested the software and incorporated the software into organizational processes. Data were collected from the 7 -year (1996 to 2002) records of the probation information systems project. The data included presentations given by the project director, an extensive set of project documents, observations of meetings, the project director's monthly reports, and 37 interviews with all of the primary decision makers. The interviews lasted 1.25 hours on average.

\subsection{Research Design}

The primary method of data gathering was through 37 semi-structured interviews conducted in 2002. Interview questions included the frequency and type of communication with other probation departments during the adoption process, and the influences and factors that guided the information system decision process. A second line of questions probed the capacity and preparedness of the departments to acquire and utilize knowledge, and determined what mechanisms in the network supported or hindered 
efforts to exploit the knowledge. Although the interviews were guided by prepared questions, a large degree of flexibility was incorporated to allow the researchers to pursue relevant issues that arose during the interview, and to allow subjects open-ended answers. Two adjacent consortia, referred to as consortium A and consortium B, with nine and six departments, respectively, were compared. Figure 1 shows the geographical distribution of the counties in the two consortia and indicates which county probation departments adopted the information system.

Interviews were conducted with the probation directors in each county in the study, as well as with senior probation officers and senior staff members who were directly involved with the adoption decision. Both the current and former state project directors were also interviewed. In addition, a former director of one of the consortium departments was interviewed due to her involvement with the early stages of the project. This range of interviews provided direct contact with the primary decision makers in all 15 departments in the study.

\subsection{Data Analysis}

Data analysis was divided into six distinct steps.

- Code-book development: A tree structure of codes was developed from the theoretical perspectives selected for this study. Codes were chosen to mark the existence of an item (e.g., system adopted) and the directionality of attributes, where applicable (e.g., positive social information processing or negative social information processing).

- Database creation: A database of all transcribed interviews, documents, and presentations was created. All transcripts and documents were named and formatted, and the database was constructed by using QSR NVIVO software.

- Knowledge-base development: Coding of the transcribed interviews and documents was performed following established standards (Miles and Huberman 1994). Multiple analysis phases applied predetermined codes and allowed codes to emerge during coding. Two researchers coded a selection of the interviews to test consistency of the coding scheme. Reliability testing determined that there were very few disagreements regarding application of the codes. Consequently, samples of the coded transcripts were double-checked for omitted codes by the second researcher, with no major omissions noted.

- Retrieval of coded text: The data were partitioned into different sets based upon system adoption. Text relevant to the hypotheses was retrieved from initial largescale sets of data from consortium A and consortium B. As analysis proceeded, other sets were created to allow different comparisons of codes, co-occurrences, and text-strings. Examples of the different data configurations examined include adopters versus non-adopters in the entire database, and non-adopters versus adopters within each consortium. 
- Text segment comparison: Documents created from retrieved text segments were compared for the occurrence, frequency, and meaning of text segments related to each research question. Relationships among specific coded texts were mapped to expose processes and reveal patterns in data. Research questions were addressed through deductive inference closely following the scientific methodology of controlled deductions in qualitative case studies outlined by Lee (1989).

- Reexamination of data: Comments, notes, and maps developed during the previous steps were used to reexamine the data and create codes for phenomena that had not been predicted. Patterns of responses were examined in the light of extant literature to determine whether other theoretical stances needed to be included in the explanation. Exemplars of particular evidence chains were sought, and other relationships among the variables were examined.

The final stage of analysis involved integrating the networking processes and proposing how these relationships were formed. An integrated model of the processes indicates how the relationships that emerge in the communication network can explain the differences between system adoption outcomes.

\section{FINDINGS}

As a group, consortium A was considered to have adopted the information system, with seven of nine participating counties adopting the system. In contrast, only the lead county of the six counties in consortium B adopted the system. Lead counties in each consortium were appointed by the state probation department on the basis of their agreement to adopt.

\subsection{Findings: Question 1}

The data indicate that the strength and degree of the social communications network is positively correlated to adoption success. In these consortia, the social communications network was characterized by both central ties from local departments to the lead department and lateral ties between members of the consortium. Changes in frequency of communication between dyads were aggregated to a comparative measure between the two consortia for central and lateral ties. Changes in the degree, or number of possible central and lateral ties, were determined prior to the start of the consortia and again as a single measure for the period during which the consortia were active. Table 1 shows the differences between consortium $A$ and consortium $B$ in the degree of lateral and central ties (out of all possible ties) and the changes in frequency of communication of those ties.

In both consortia, network strength increased after the network organization form was initiated. This increase was greater in consortium A for both formal, central ties and for informal, lateral connections between local departments. In consortium A, a total of six formal consortium meetings were held in the five years since the beginning of the 
Table 1. Comparison of Central and Lateral Network Ties

\begin{tabular}{|c|l|c|c|c|}
\hline \multicolumn{2}{|c|}{} & $\begin{array}{c}\text { Prior to } \\
\text { Consortia } \\
\text { Formation }\end{array}$ & \multicolumn{2}{|c|}{ During Consortia Period } \\
\cline { 3 - 6 } & $\begin{array}{c}\text { Network Degree } \\
\text { Existing ties of } \\
\text { (Possible ties) }\end{array}$ & $\begin{array}{c}\text { New ties } \\
\text { created }\end{array}$ & $\begin{array}{c}\text { Network Strength } \\
\text { Ties that Increased in } \\
\text { communication fre- } \\
\text { quency of (possible ties) }\end{array}$ \\
\hline $\begin{array}{c}\text { Consortium A } \\
\text { (high adoption) }\end{array}$ & Central Ties & 5 of $(8)$ & 3 & 8 of $(8)$ \\
\cline { 2 - 6 } & Lateral ties & 18 of $(28)$ & 4 & 9 of $(28)$ \\
\hline $\begin{array}{c}\text { Consortium B } \\
\text { (non-adoption) }\end{array}$ & Central Ties & 2 of $(5)$ & 3 & 2 of $(5)$ \\
\cline { 2 - 6 } & Lateral ties & 4 of $(10)$ & 0 & 0 of $(10)$ \\
\hline
\end{tabular}

system implementation. All eight of the local departments of consortium A reported an increase in contact with the lead department and roughly one-third of the potential lateral ties increased in communication frequency. At the consortium network level, both frequency of communications and number of possible connections increased.

In contrast, no formal activities were held in consortium $B$ after the initial planning meetings. Department directors traveled to other counties to examine the software, but no meetings among all consortium members were organized. None of the departments in consortium $B$ reported an increase in the number of lateral connections. The networklevel changes in strength and degree of connections in consortium B were less than was observed in consortium A.

Formal meetings appear to have provided one mechanism through which informal connections could be initiated. Notably, the greatest difference between the two consortia is in number and strength of lateral ties. This direct communication among local member organizations may represent a tertius iungens orientation toward linking people by facilitating coordination between connected network members (Obstfeld 2005 ) and may provide a mechanism by which knowledge is transferred.

\subsection{Findings: Question 2}

Data indicate that the social communication networks influenced system adoption by social information processing related to the PROBER project. All departments involved in the project reported both positive and negative comments about the PROBER system. In consortium A, almost all of the directors commented on a specific benefit the system would provide. These included managing caseloads, increasing efficiency for probation officers, financial benefits from automating restitution, and involving officers more directly in the cases. The statement that best captures the most common attitude was that benefits "on the positive side, I think outweigh [the negative]."

The directors acknowledged that they had heard negative comments, but these were mostly minor implementation difficulties, complaints from officers about having to 
perform clerical work, and resistance to change, rather that substantive doubts about the system. For example,

There was a lot of input, we're not data-entry clerks, we're used to dictating our words, or writing out our letter long-hand and give it to the secretary, and some of us can't type, and if you're hunting and pecking when you input this information, it's going to take a long time. It changes the job-requirement a little bit; it changes the skills you need to bring to the job. In the past, you didn't have to know how to type to be a probation officer; nowadays it sure helps. There was a lot of frustration.

In contrast, directors in consortium B were far more ambivalent about the project and reported vague comments about what they had heard (e.g. "some people like it and some didn't like it"). Even in cases where they reported hearing positive attitudes, they included a negative counterpoint, such as wanting to wait until the bugs were fixed, expressing concern that the system wouldn't support departmental processes, or worrying that the system was too complex, inflexible, or limited in function.

Negative social information processing can also impact members of a strong communication network. Directors who were critical of the PROBER system argued for an alternative automation system developed by a department in the eastern part of the state. This alternative system was less expensive, currently available, and purportedly met state reporting standards. ${ }^{1}$ The proposal to adopt the alternative system included information critical of the PROBER system and resulted in a resolution to stop further development and deployment of PROBER. Considerable discussion of the alternative system caused controversy and confusion and required that meetings be arranged to resolve the confusion.

\subsection{Findings: Question 3}

In general, stronger social communication networks increased organizational ability to acquire, assimilate, and exploit new knowledge. A general assessment of ACAP for each department was estimated and compared using characteristics representative of the ability to acquire, assimilate, and exploit knowledge (Table 2). Computer experience and use of other information systems were the surrogate measures for prior knowledge. Whether the department obtained the necessary hardware prior to obtaining the software, the existence of local IS department support, the interest level of the officers and staff, and sufficient time for training were characteristics related to a department's ability and willingness to assimilate and exploit new knowledge. Table 2 summarizes the ACAP items aggregated within consortia $\mathrm{A}$ and $\mathrm{B}$.

'An independent evaluation subsequently revealed that the alternative system was subject to system crashes, did not meet state standards, nor did it allow electronic reporting. 
Table 2. Absorptive Capacity (ACAP) Characteristics

\begin{tabular}{|c|c|c|}
\hline ACAP Items & $\begin{array}{c}\text { Consortium A } \\
\text { (high adoption) } \\
\text { Number of counties of } \\
\text { classification/total counties }\end{array}$ & $\begin{array}{c}\text { Consortium B } \\
\text { (non-adoption) } \\
\text { Number of counties of } \\
\text { classification/total counties }\end{array}$ \\
\hline $\begin{array}{l}\text { User computer } \\
\text { experience }\end{array}$ & High $2 / 9 ;$ Mixed $4 / 9 ;$ Low $3 / 9$ & High $0 / 6 ;$ Mixed $3 / 6 ;$ Low $3 / 6$ \\
\hline $\begin{array}{l}\text { Prior or current use of } \\
\text { similar systems }\end{array}$ & $\begin{array}{l}\text { had used or are currently using } \\
\text { some type of automation } \\
\text { systems } 5 / 9\end{array}$ & $\begin{array}{l}\text { Had used or are currently using } \\
\text { some type of automation } \\
\text { systems } 6 / 6\end{array}$ \\
\hline IS department support & Good 6/9; Limited 3/9 & $\begin{array}{l}\text { Good } 0 / 6 ; \text { Limited } 3 / 6 ; \text { Low } \\
1 / 6 ; \text { using external contactor } \\
2 / 6 \text {. }\end{array}$ \\
\hline $\begin{array}{l}\text { Obtained hardware } \\
\text { prior to software }\end{array}$ & Purchased or upgraded PCs $5 / 9$ & Purchased or upgraded PCs $4 / 6$ \\
\hline
\end{tabular}

As expected, the presence of prior knowledge in the form of computer experience was positively associated with adoption. In consortium $A$, a majority (six of nine) of directors rated their employees as having high computer experience (two departments) or as having a mixture of experienced and inexperienced computer users (four departments). The opposite was reported in consortium B with all of the six departments considering their employees' computer experience to be mixed or low.

When previous or current use of automation systems used in probation departments (e.g., spreadsheets developed in-house, the previous County Automation Project, the Correction Project, and the Youth Assessment Project) was examined, there was no apparent relationship with adoption of the PROBER system. Consortium B actually had a higher proportion of departments that had used or were currently using some type of information system.

IS department competence was also correlated with adoption. In consortium A, six of the nine departments had good relationships with competent MIS departments. Interestingly, the three departments who felt their MIS support was limited did adopt the system, indicating that this was not necessarily a roadblock to adoption. Therefore, the limited MIS support reported in consortium B does not explain the non-adoption behavior.

Finally, a majority of departments in both consortia obtained sufficient computer and network hardware, indicating that this was not a factor for the differences between the consortia.

\subsection{Summary of Findings}

Considered individually, the theories informing the three research questions could be used to explain some of the observed adoption differences between the consortia. 
But these data also reveal that there are interactions within the communication network that enhance or mitigate the impact of each theory. Illuminating these interactions allows for a richer explanation of the processes by which the social communication network contributes to organizational adoption. For example, network degree (number of possible network connections) increases the variety of knowledge sources. Network strength (frequency of contact) increases the exposure to knowledge, attitudes and behaviors of network members. Together, these network characteristics increase social information processing which, in turn, increases or decreases network strength depending on the valence of the social information processing. In addition, dimensions of absorptive capacity can cross organizational boundaries when a strong communication network is present, so that the capacities of network members are enhanced. Network members who have positive attitudes and behaviors are more likely to provide knowledge and technical support to other network members and network members who received support generally exhibited positive attitudes. This feedback between social information processing and absorptive capacity within the social communication network points to the opportunity for these theories to be integrated into a more fully explanatory model.

\section{INTEGRATED MODEL}

Our data suggest that the two networks studied had dramatically different adoption outcomes. As with any study of real-world phenomena, many possible explanations exist for the observed differences. But an examination of the fixed attributes of the probation departments, including the size, number of employees, number of clients served, budget, and distance from other probation departments in the same consortia, did not reveal any patterns that could explain the difference in outcome between the consortia. The number of counties in each consortium was not a determining factor, given that three counties in a four-county consortium in the eastern part of the state adopted the system. In that consortium, the lone non-adopting county had a functioning information system prior to the start of the state consortium initiative.

An integrated organizational adoption model (Figure 3) shows the interactions of the processes examined in this research. This model presents a set of propositions about the specific relationships among network strength, social information processing, absorptive capacity, and organizational adoption.

In a distributed organizational environment, the use of formal communications structures and the subsequent creations of informal ties can result in a strong, dense network with central and lateral ties that provide the connections through which social influence and knowledge flow. The content of the social influence variables has a positive or negative valence. In this case, positive content is supportive of system adoption, whereas negative content contains information opposing system adoption. The strength and density of the communication network alters the potential of social influence variables to affect adoption via social information processing. Stronger network connections increase the likelihood that particular social influence variables will be received from different sources, and also increase the frequency with which such transfers occur. In consortium $\mathrm{A}$, one director commented that 


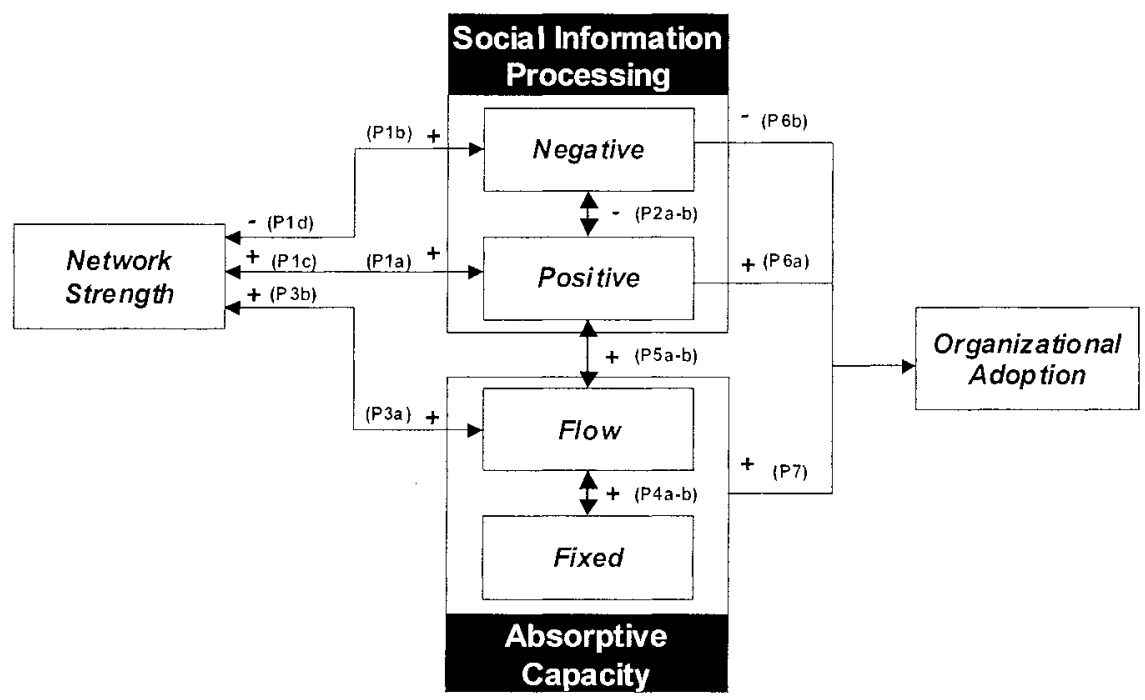

Figure 2. Integrated Organizational Adoption Model

[The consortium] creates an environment where directors can have a forum to discuss the issues, the goods and the bads about it, and be able to go back to their county and make some decisions along with the people that they have to make those decisions with. I mean, that's the best piece about it, as far as I'm concerned, because you go to a meeting and I can get some pretty good information about the system, and then come back to my own county and say, well this is how it works, this is what it can do for us.

Simultaneously, knowledge transfer in the form of social influence, norms, and attitudes strengthens or weakens communication network ties, depending on its valence. Generally, positive knowledge flows tend to increase network strength, and negative knowledge flows result in fewer connections with less frequent communications.

The integrated model represents SIP as composed of positive and negative valences that interact. Strongly positive components are those that support adoption, whereas negative components are those that oppose adoption. In this case study, some directors were strongly affected by negative attitudes. In one instance, a director in consortium A noted that even though negative comments had affected his personal opinion, other directors had disregarded the comments

You know, I can remember who had a lot of complaints about it, but I can't remember what [the complaints] were. And the person that had a lot of complaints is a person i respect and I know wouldn't steer counties wrong, so I put a lot of credibility into that person's comments ... but yet another director heard those same comments at the same meeting, and went ahead and purchased the software knowing full well that there were these alleged problems with it. 
But during an extended adoption process, social information processing supported by a strong network can result in individuals altering their attitudes. Exposure to frequent positive attitudes, or similar attitudes from diverse sources, can overcome initial negative attitudes adopted from even respected sources. The same director quoted above altered his decision when the positive comments he had heard eventually outweighed the negative comments.

\section{I talked to my data processing director and the plan for us was to wait a year or so to see how the counties in the pilot project did and maybe some other counties... what they thought of it.... had heard enough good things about it last year I went and tried to get it for our department.}

This indicates that the transfer of attitudes and social influences of a positive valence can supplant negative attitudes and vice versa, particularly in a dense network with strong ties.

We propose that each absorptive capacity dimension can be linked to aspects of the communication network. Greater network density increases the diversity of sources and is consistent with the acquisition dimension of ACAP. Assimilation of knowledge is linked to the attitude regarding IT, prior computer experience, and learning (e.g., training). The transformation dimension requires the internalization of knowledge as reflected by changes in internal processes. Knowledge exploitation is supported by social integration mechanisms within the organization and interorganizational networks that increase employee interaction and promote problem solving.

Our data indicate that departments relied on knowledge from members of their communication networks for both the decision to adopt and for the assimilation and exploitation of the software. This suggests that the previous conceptualization of ACAP as fixed within the organization is incomplete. Elements that enable an organization to assimilate, transform, and exploit knowledge can be transferred through a social communication network and comprise dynamic $A C A P$. The mobility of dynamic ACAP through a network differentiates it from fixed $A C A P$, which resides within the organization and cannot easily be shared. The ability of organizations to augment internal ACAP deficiencies by obtaining knowledge from the network increases the chances of a positive adoption result. In one case, a senior officer stated

But I deal with the counties all over, anyone who has a question about the system and [my director] has been willing to send myself and [my coworker] to go anywhere that people need assistance.

Fixed ACAP is comprised of prior information system experience, interest, computer competence, and computer resources. High levels of these capacities provide the potential to extend dynamic ACAP with problem solving, training, and system support through network connections. Conversely, network members can overcome deficiencies in fixed ACAP through communication network connections. Advice about specific problems and recommended changes in organizational procedures to better utilize the system can overcome low user computer experience. Thus, capacities grounded in the organization, such as technical and problem-solving support, can 
become knowledge exchange processes that move through the network and increase an organization's ability to assimilate and exploit the system. By increasing experience, knowledge, and problem-solving capacities in the beneficiary organization, dynamic ACAP increases the fixed ACAP of the recipient. All of the adopting counties in consortium A relied heavily on other consortium members for advice and help. One director reported that the departments that impacted his decision were "probably those counties that were into the system and had initiated it and I was able to get some answers from; they had some experience going through the system."

As shown in Figure 3, a reciprocal relationship exists between the processing of social information (SIP) and the organizations' ability to acquire, assimilate, and exploit knowledge (ACAP). The ability of SIP and knowledge transfer to overcome a low ACAP dimension was demonstrated by the decision to adopt the software in the three departments in consortium $A$ that had mixed levels of interest in the system. These three departments all had poor experiences with prior software systems for other functions, yet through their interactions with departments in the consortium, they had acquired knowledge leading to a positive adoption result. In consortium $B$, where there were fewer network ties and most of those were weaker, negative experience with prior software and negative comments regarding the PROBER system were not overcome by positive SIP and ACAP support flowing through the network.

Organizations processing positive social influence variables are potentially more likely to contribute dynamic ACAP to network members. At the same time, the flow of ACAP in the network increases the amount of positive information processed by network members. For example, a network member who is receiving problem-solving or technical help will likely communicate positive attitudes and normative behaviors to other network members. This is exhibited in comments such as

I think what the consortium does, it gives the other probation directors some kind of feeling that there are other people out there willing to help them out when they are having a problem. The biggest fear, and it is a major decision, whether you are going to commit your department to an automation system, either this one or that one, and whenever you can feel secure that, number one, there are other people you respect who are doing it and have made that decision, you feel a little bit better about your own decision. And, then when you need it, those people are there and you can call on them for help; it makes you more willing to be a willing participant in the process.

The positive or negative valence of the content of social information that is processed has a direct influence on the likelihood of adoption. Positive attitudes and supporting norms increase adoption; negatively oriented information decreases adoption likelihood. Typical of the evidence of the impact of negative SIP

There was a point in the process where two directors got disenchanted with the PROBER process, and they were significant directors, they are people who could influence people heavily. One of them went to the meeting and made a comment like, "You have to be nuts to implement PROBER". ... he was also very energetic and sometimes he speaks before he realizes the implications of 
what he's talking about. So, he made that comment, he scared off [a probation department]. [The director of that department] definitely was thinking about PROBER and now they scared [the director] so much she didn't know what to do, so she was going to go with the alternative system.

An organization's ability to acquire, assimilate, transform, and exploit knowledge determines its overall absorptive capacity. System adoption is frequently a complex process requiring new information, learning, and assimilation of new skills, as well as changes in internal processes and organizational structures. The capacity to accomplish these goals is directly related to the willingness and ability to adopt a new information system.

The integrated model identifies some of the processes and interactions inherent in social communication network theories and provides a more complete explanation of the differences within and between the networks than any of the theories alone. The model reflects our belief that organizational-level adoption can be subsumed under general network theories regarding interactions of network processes that support or weaken system adoption initiatives.

\section{CONCLUSIONS}

By examining communication processes and interactions of organizations from the perspective of the social communication network, this study demonstrates how networks can influence the agility of organizations to acquire and assimilate new ideas and adopt innovations such as information systems. This research identifies the interaction of network characteristics, social communication processes, and organizational capabilities and shows that strong and dense communication networks facilitate knowledge flows that enhance social information processing and support the flow of elements of absorptive capacity in the network.

Social information processing of pro-adoption social influence, social norms, attitudes, and behaviors can increase the chance of positive adoption outcomes. Social information processing is a crucial aspect of the adoption process during which supporting or discouraging knowledge interacts as decisions regarding system adoption are made. Network members may attend to different information, depending on the specific source, the variety of sources, or the frequency of exposure to the information. Supporting knowledge transferred through the network may displace negative attitudes toward adoption. The opposite process, in which negative attitudes, beliefs, and behaviors are transferred and negatively influence adoption, can also occur. The strength and density of the social communication network partially determines the influence of social information processing.

An organization's agility is based, in part, on it's ability to acquire, assimilate, transform, and exploit knowledge, and can be increased through strong and dense network ties to other organizations. Interorganizational networks can also reinforce deficient absorptive capacity dimensions in connected organizations. In the case of organizational IS adoption, this dynamic ACAP may take the form of technical support, implementation procedures, transfer of knowledge pertaining to software customization, 
and problem solving. This extension of the ACAP construct across organizational boundaries supplies a mechanism by which communication networks can support IS adoption across organizational boundaries. In groups of autonomous organizations, the fixed ACAP of a specific member can be enhanced by dynamic ACAP from other members.

The integrated adoption model presented in this research proposes interactions within the network adoption process by which social influence variables become important. The interactions shown in this model indicate that these social communication network theories are not separate, independent processes, but are actually intertwined. When applied to the adoption process, network communication theories must be considered together in order to fully understand the knowledge flows that increase the abilities of an organization to acquire and exploit new knowledge leading to organizational information system adoption.

\section{REFERENCES}

Baker, W. E. "The Network Organization in Theory and Practice," in Networks and Organizations: Stmucture Form and Action, N. Nohria and R. G. Eccles (Eds.), Boston: Harvard Business School Press, 1992, pp. 397-429.

Chau, P. Y. K., and Tam, K. Y. "Factors Affecting the Adoption of Open Systems: An Exploratory Study," MIS Quarterly (21:1), March 1997, pp. 1-24.

Cohen, W. M., and Levinthal, D. A. "Absorptive Capacity: A New Perspective on Learning and Innovation.," Administrative Science Quarterly (35), 1990, pp. 128-152.

Compeau, D. R., and Higgins, C. A. "Computer Self-Efficacy: Development of a Measure and Initial Test," MIS Quarterly (19:2), 1995, pp. 189-211.

Fichman, R. G. "The Diffusion and Assimilation of Information Technology Innovations," in Framing the Domains of IT Management: Projecting the Future... Through the Past, R. W. Zmud (Ed.), Cincinnatio, OH: Pinnaflex Educational Resources, Inc., 2000, pp. 105-127.

Fichman, R. G. "Going Beyond the Dominant Paradigm for Information Technology Innovation Research: Emerging Concepts and Methods," Journal of the Association for Information Systems (5:8), 2004, pp. 314-355.

Gallivan, M. J. "Organizational Adoption and Assimilation of Complex Technological Innovations: Development and Application of a New Framework," Data Base for Advances in Information Systems (32:3), 2001, pp. 51-85.

Grandori, A., and Soda, G. "Inter-firm Networks: Antecedents, Mechanisms and Forms," Organization Studies (16:2), 1995, pp. 183-205.

Gulati, R., Nohria, N., and Zaheer, A. "Strategic Networks," Strategic Management Joumal (21:3), 2000, pp. 203-215.

Kraut, R., Rice, R. E., Cool, C., and Fish, R. "Varieties of Social Influence: The Role of Utility and Norms in the Success of a New Communication Medium," Organization Science (9:4), 1998, pp. 437-453.

Larsen, T. J. "The Phenomenon of Diffusion: Red Herrings and Future Promise," in Diffusing Software product and Process Innovations, M. Ardis and B. Marcolin (Eds.), Boston: Kluwer Academic Publishers, Boston, 2001, pp. 35-50.

Lee, A. S. "A Scientific Methodology for MIS Case Studies," MIS Quarterly (13:1), March 1989, pp. 33-49.

Lyytinen, K., and Damsgaard, J. "What's Wrong with the Diffusion of Innovation Theory?," in Diffusing Software Product and Process Innovations, M. Ardis and B. Marcolin (Eds.), Boston: Kluwer Academic Publishers, 2001, pp. 173-190. 
Matusik, S., and Heeley, M. B. "A Multilevel Theory of Absorptive Capacity in the Software Industry," Journal of Management, 2005 (forthcoming).

McKelvey, B. "Quasi-Natural Organization Science," Organization Science (8:4), 1997,pp. 352 380.

McMaster, T. "The Illusion of Diffusion in Information System Research," in Diffusing Software Product and Process Innovations, M. Ardis and B. Marcolin (Eds.), Boston: Kluwer Academic Publishers, 2001, pp. 67-83.

Miles, M. B., and Huberman, A. M. Qualitative Data Analysis: An Expanded Sourcebook (2 ed.), Beverly Hills, CA: Sage Publications Ltd., 1994.

Monge, P. R., and Contractor, N. Theories of Communication Networks, New York: Oxford University Press, 2003.

Obstfeld, D. "Social Network, the Tertius Imngens Orientation, and Involvement in Innovation," Administrative Science Quarterly, 2005 (forthcoming).

Pare, G., and Elam, J. J. "Using Case Study Research to Build Theories of IT Implementation," in Information Systems and Qualitative Research. A. Lee, J. Liebenau and J. I. DeGross (Eds.), London: Chapman \& Hall, 1997, pp. 542-568.

Rice, R. E. "Individual and Network Influence on the Adoption and Perceived Outcomes of Electronic Messaging," Social Networks (12:1), 1990, pp. 27-55.

Rice, R.E. "Using Network Concepts to Clarify Sources and Mechanisms of Social Influence," in: Progress in Communications Science, W.J. Richards and G. Barnett (eds.), Ablex, Norwood, 1993, pp. 43-62.

Rice, R. E., and Aydin, C. "Attitudes toward New Organizational Technology: Network Proximity as a Mechanism for Social Information Processing," Administrative Science Quarterly (36:2), 1991, pp. 219-244.

Rogers, E. Diffusion of Innovations $\left(5^{\text {th }}\right.$ ed.), New York: Free Press, 2003.

Sambamurthy, V., Bharadwaj, A., and Grover, V. "Shaping Agility Through Digital Options: Reconceptualizing the Role of Information Technology in Contemporary Firms," MIS Quarterly (27:2), June 2003, pp. 237-263.

Stuart, W. D., Russo, T. C., Sypher, H., Simons, T. E., and Hallberg, L. K. "Influences of Sources of Communication on Adoption of a Communication Technology," in Diffusing Software Product and Process Innovations, M. Ardis and B. Marcolin (Eds.), Boston: Kluwer Academic Publishers, Boston, 2001, pp. 191-204.

Sussman, S. W., and Siegal, W. S. "Informational Influence in Organizations: An Integrated Approach to Knowledge Adoption," Information Systems Research (14:1), March 2003, pp. $47-65$.

Swan, J., Newell, S., and Robertson, M. "Interorganizational Networks and Diffusion of Information Technology: Developing a Framework," in Information Systems Innovation and Diffusion: Issues and Directions, T. J. Larsen (Ed.), Hershey, PA: Idea Group Publishing, 1998, pp. 220-250.

Taylor, S., and Todd, P. "Assessing IT Usage: The Role of Prior Experience," MIS Quarterly $(19: 4), 1995$, pp. 561-570.

Thompson, R. L., Higgins, C. A., and Howell, J. M. "Personal Computing: Toward a Conceptual Model of Utilization," MIS Quarterly (15:1), March 1991, pp. 125-143.

Triandis, H. C. "Values, Attitudes, and Interpersonal Behavior," in Nebraska Symposium on Motivation: Beliefs, Attitudes, and Values, Lincoln, NE: University of Nebraska Press, 1980, pp. 195-259.

Van Alstyne, M. "The State of Network Organization: A Survey of Three Frameworks," Joumal of Organizational Computing (7:3), 1997, pp. 83-152.

Venkatesh, V., Morris, M. G., Davis, G. B., and Davis, F. D. "User Acceptance of Information Technology: Toward a Unified View," MIS Quarterly (27:3), 2003, pp. 425-478.

Zahra, S. A., and George, G. "Absorptive Capacity: A Review, Reconceptualization and Extension," Academy of Management Review (27:2), April 2003, pp. 185-203. 


\section{ABOUT THE AUTHORS}

Dirk S. Hovorka is a Ph.D. candidate at the Lecds School of Business, University of Colorado, Boulder. His research includes influences of social networks on knowledge exchange, information systems in science, and the philosophical foundations of IS research.

Kai R. Larsen is an assistant professor of Information Systems in the Leeds School of Business, University of Colorado, Boulder. His research interests center around interdisciplinary approaches to information systems implementation and interorganizational networks. 